\title{
As políticas linguísticas e de ensino de línguas em Timor-Leste: desafios de um contexto multilingue
}

\author{
Alan Silvio Ribeiro Carneiro*
}

RESUMO: O objetivo deste artigo é apresentar brevemente a situação atual do processo de implementação das políticas linguística e de ensino de línguas em Timor-Leste, a partir de dados coletados em diversas fontes, principalmente documentos, e também pela observação direta ao longo de um ano de trabalho, da situação do ensino de língua portuguesa no país. Para tal, este artigo aponta breves notas sobre a história da língua portuguesa em Timor-Leste e a política linguística atual e de ensino de línguas, para então discutir os desafios colocados pelo contexto multilingue timorense para o desenvolvimento do ensino das línguas nativas e oficiais.

Palavras-chave: Timor-Leste; Política Linguística; Ensino de Línguas; Multilinguismo

ABSTRACT: The main aim of this paper is to present briefly the current situation of the process of implementation of Timor-Leste's language policy and language teaching policy, based on the collection of different data, mainly documents, and also based on the direct observation, in one year of work, of the teaching situation of Portuguese language in the country. In this sense, at first is pointed out some brief notes about the history of Portuguese language in the country and the current language policy and language teaching policy, discussing at the end the challenges of the Timorese multilingual context to the development of the official and native language teaching.

Keywords: Timor-Leste; Language Policy; Language Teaching; Multilingualism.

Pós-Graduando na Universidade Estadual de Campinas (UNICAMP) na área de Teoria e História Literária, entre os anos de 2006 e 2009, a nível de mestrado, com um trabalho em fase de conclusão e professor cooperante, com vínculo de bolsista da Coordenação de Aperfeiçoamento de Pessoal de Nível Superior (CAPES), na Universidade Nacional Timor Lorosa'e (UNTL), entre os anos de 2008 e 2009. 


\section{Introdução}

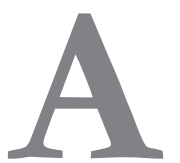

o chegar no aeroporto em Díli, Timor-Leste, as placas de propaganda indiciam uma complexa situação linguística: o anúncio de uma instituição financeira indonésia, o banco Mandiri, está em indonésio; curiosamente a propaganda do banco Australian and New Zealnd (ANZ) está em português, a língua oficial; o de uma organização não-governamental (ONG) norte-americana Buy Local que atua no país está em inglês, com a tradução para a língua co-oficial, o tétum.

Ao percorrer a cidade, a diversidade de línguas utilizadas não só nas placas e sinalizações, mas também nos diversos contextos de interação surpreende ainda mais: pessoas falando em tétum nas ruas, nas feiras e nas casas; professores portugueses e brasileiros ensinando e interagindo em língua portuguesa nas universidades e em cursos de formação de professores; trabalhadores internacionais dos mais diversos países conversando em inglês nos restaurantes, nas agências internacionais e nas sedes de ONGs; comerciantes de diferentes nacionalidades, mas principalmente indonésios e chineses, utilizando o indonésio e o inglês, dentre os quais ainda se veem alguns que utilizam o hakka ou o yue, línguas vindas do sul da China que estão presentes no país desde tempos remotos.

Este é o panorama sociolinguístico da capital timorense, onde quem quiser interagir com toda a diversidade de pessoas deste ambiente deve dominar estas línguas, pois, apesar de existirem muitos sujeitos multilíngues, alguns são monolíngues. Embora constitucionalmente, segundo o Artigo 13, as línguas oficiais de Timor-Leste sejam o português e o tétum (Timor-Leste, 2002, p. 12), o estatuto transitório de línguas de trabalho dado ao indonésio e ao inglês no Artigo 159 (Ibid., p.47) faz com que os indonésios, os antigos invasores, cientes do conhecimento da população do indonésio, ignorem as duas línguas oficiais com que, muitas ONGs e agências internacionais de cooperação e desenvolvimento, provindas dos países desenvolvidos, optem pelo uso do inglês e do tétum, ignorando a língua portuguesa. Neste complexo quadro, o português fica mais restrito, ainda que com graus diferenciados de uso, aos espaços escolares e institucionais e principalmente onde se faz necessária a interação com assessores e cooperantes dos países lusófonos.

Mas a situação sociolinguística de Díli é só a faceta mais visível da complexidade linguística de Timor-Leste; ao subir as montanhas e adentrar o interior do país, começa a aparecer uma variedade de línguas, que sem contar as mencionadas anteriormente, totalizam quinze línguas diferentes pertencentes às duas grandes famílias austronésia e papua (línguas 
austronésias: bekais, tétum, galoli, wetar, kawaimina, habun, makuva, tukudede, kemak, mambai, idalaka; línguas papuas: bunak, makasai, fataluku, makalero) sendo que, parte destas línguas apresenta ainda diferentes dialetos: o tétum e o mambae com três dialetos diferentes cada; as cadeias dialetais kawaimina (kairui - waima'a - midiki - naueti) e idalaka (idaté - lakalei - isni) que são compostas por quatro e três dialetos respectivamente, sendo que do isni ainda deriva o isoleto lolein, falado em Díli; afora estas, o Wetarês, língua da ilha de Ataúro, se subdivide em três dialetos na própria ilha e mais um na ilha de Timor (dadua) (Hull, 1998 apud Engelenhoven, 2006)

Este contexto linguístico desde o início do processo de independência de Timor-Leste tem colocado uma série de questões a respeito da política linguística a ser adotada e desenvolvida no país, assim como da política de ensino de línguas a ser trabalhada nos ambientes escolares.

A problemática que envolve não só as questões de língua, mas também as questões relacionadas à memória histórica e ao passado, à soberania e a independência política atual e ainda à complexa geopolítica local e global na qual Timor-Leste se insere faz com que o debate sobre a língua seja constantemente retomado e seja objeto de diversas polêmicas no processo de construção da nação entre os diversos atores sociais timorenses e internacionais que intervêm neste processo.

A implementação de uma política linguística e de ensino de línguas e a construção de um sistema educacional em Timor-Leste ainda estão em andamento, exigindo a constante reflexão e o remodelamento das políticas de acordo com as necessidades que tem surgido ao longo do processo. O objetivo deste artigo é apresentar um retrato desta situação neste momento, tendo como foco o ensino de língua portuguesa e a relação deste com o contexto linguístico, do qual este ensino faz parte em Timor-Leste. Para tal, apontam-se breves notas sobre a história da língua portuguesa no país e a política linguística e de ensino de línguas atuais, para então discutir-se o processo de reintrodução da língua portuguesa no sistema escolar e os desafios políticos colocados pelo contexto multilinguístico existente no país. 
2. Breve história da língua portuguesa e da política linguística atual de Timor-Leste

Timor-Leste é um pequeno país localizado no Sudeste Asiático, ocupando aproximadamente dois terços da ilha de Timor, que se localiza no arquipélago das Pequenas Ilhas da Sonda, a leste das Grandes Ilhas da Sonda, as ilhas de Samatra, Bornéu, Java e Celebes (Atlas de Timor-Leste, 2002). O pequeno país tem 14.919 quilômetros quadrados e uma população de 1.080 mil pessoas(Timor-Leste em Números, 2008), apresentando neste momento o IDH mais baixo do Sudeste Asiático (Human Development Report 2007/2008, 2007) e um alto índice de crescimento populacional (Bulatao, 2008), o que coloca uma série de problemas políticos para se pensar o futuro do país.

Timor-Leste se destaca no contexto por ser o único país colonizado por portugueses na região e por ter uma língua latina, o português, como língua oficial, em uma região onde há uma grande diversidade linguística e línguas regionais fortes e onde dentre a as línguas europeias que se fixaram predomina o inglês como língua oficial, como no caso da Malásia e de Cingapura e como segunda língua no ensino como, por exemplo, na Indonésia e na Tailândia. Afora isso, o fato de ser um país católico, onde outras religiões predominam como o islamismo, na referida Malásia e na Indonésia ou ainda o budismo, como na Tailândia e no Cambodja, faz com que o país se torne um caso muito específico, se pensado a partir de uma ótica comparativa com o seu bloco regional (Atlas de Timor-Leste, 2002).

Isso remete ao fato de que, embora a associação de Timor-Leste a Portugal tenha se dado em conjunto com o início do desenvolvimento da presença portuguesa na região no século XVI, ao contrário do que aconteceria em outros lugares, onde esta presença se reduziria progressivamente com a disputa comercial com os ingleses e holandeses; a partir do século XVII em Timor-Leste esta presença foi se ampliando, assim como em Goa e em Macau, definindo e delimitando deste modo os domínios coloniais portugueses na Ásia ${ }^{1}$. A língua portuguesa que neste período gozou de prestígio e de valorização na região, sendo a língua da diplomacia e dos negócios, resistiu ainda um pouco mais, até o século XVIII, servindo como língua de comunicação em diversos lugares da Índia até a

1 Apresenta-se neste tópico um panorama geral desta história, para maiores informações sobre a história dos portugueses no oriente Cf. Marques (1998-2003). 
China, o que contribuiu para a formação de crioulos indo-portugueses, malaio-portugueses e sino-portugueses ${ }^{2}$.

Embora o sândalo branco que atraíra os portugueses para Timor aos poucos fosse desaparecendo, a chegada do primeiro governador em 1701 com a formação logo em seguida de um exército local com nativos que, embora modificado, iria resistir ao longo de todo período de relação colonial, assim como a assinatura de termos de vassalagem entre os reis locais e os reis de Portugal, formaram as bases para que ao longo dos séculos as relações dos timorenses com os portugueses transcendesse a relação colonial. Neste sentido, os portugueses, inclusive, foram incorporados no lendário cosmológico de alguns dos povos timorenses, o que contribuiu também para que a língua portuguesa ocupasse uma posição privilegiada sendo usada como a língua da administração e do ensino, mas também se fazendo presente nos empréstimos vocabulares de rituais importantes como os de casamento e funeral.

Embora os portugueses tenham feito muito poucas escolas durante o período colonial (ainda que pese o fato de que nos últimos anos deste período tenham sido fundadas muitas salas de aula) o acesso ao ensino pelos chefes locais e pelos seus filhos sempre permitiu a formação de uma elite que falava a língua portuguesa e tendo em vista o fato de que, em geral, este ensino era oferecido pela igreja católica, que professava a fé cristã. Foi a progressiva ampliação do acesso ao ensino da língua portuguesa e da fé católica que permitiu que o domínio português no território timorense fosse se ampliando, inclusive delimitando as relações entre os diversos grupos etno-linguísticos do país. Em momentos cruciais da história de Timor, como nas diversas revoltas coloniais e na Segunda Guerra Mundial, a lealdade de parte dos timorenses aos portugueses, construída nestas bases, é que fez com que o território permanecesse unificado e sob o domínio português, do mesmo modo foi a língua portuguesa e a fé católica, símbolos da especificidade timorense em relação aos indonésios, que alicerçaram a luta política de resistência durante os 24 anos de ocupação indonésia, de 1974 a 1999.

Foi neste sentido que em 25 de agosto de 2000, o linguista australiano Geoffrey Hull (2001) deu uma conferência, no Congresso Nacional do Conselho Nacional da Resistência Timorense, que serviu de base cien-

2 Para a história da língua portuguesa na Ásia, Cf. Marques (1998-2003), em Timor-Leste, Cf. Thomaz (2002) e os artigos publicados na Revista Camões (2001) que serviram de base para estes breves apontamentos históricos. 
tífica para a atualização da decisão política, tomada 25 anos antes, quando da declaração da independência timorense em 27 de novembro de 1975, de adoção da língua portuguesa e da língua tétum como línguas oficiais. Nesta conferência, Hull (2001) evidenciou não só os fatores históricos e sociais que justificavam a escolha da língua portuguesa como línguas oficiais, mas também explicitou a relação de dependência entre o tétum e o português em Timor-Leste, uma vez que o tétum oficial, originalmente era uma língua franca local que se desenvolveu ao longo dos séculos pelo contato estreito com a língua portuguesa.

Hull (2001) justificou ainda que dentre as razões para não adotar o inglês e o indonésio como línguas oficiais se destacam o fato da primeira ser uma língua que tende a suplantar pelo seu prestígio as outras línguas locais, gerando nos falantes um complexo de inferioridade com relação às suas línguas maternas e a segunda por ter uma relação direta com a política genocida implementada por Suharto em Timor-Leste, no período da ocupação, representando também uma política linguística de desvalorização das línguas locais em nome da unidade nacional.

Com estas notas é mais fácil compreender as origens e o sentido da política linguística apresentada na Constituição de Timor-Leste, no entanto, continua sendo um desafio a implementação desta política, pois afora o embate ideológico e político a ser travado continuamente, tendo em consideração estas problemáticas, novas questões surgem constantemente quando se avalia o desenvolvimento da política e quando entra em questão as diretrizes educacionais e as práticas de ensino a serem adotadas nas escolas.

\section{As políticas linguística e de ensino de línguas}

A complexidade sociolinguística original de Timor-Leste somada à presença das diferentes línguas que ao longo da história se inseriram no país tem exigido uma série de diretrizes complementares que dão suporte a política linguística apontada na constituição timorense, dentre estes instrumentos vale destacar: do ponto de vista institucional, o Decreto 1/2004 que regulamenta o uso das línguas citadas na constituição, tratando também do padrão ortográfico do tétum e do papel do Instituto Nacional de Linguística (INL), como guardião das línguas nacionais e do ponto de vista educacional, o Plano Curricular para o Ensino Primário de 2005 e a Lei de Bases da Educação de 2008 que determinam as línguas a serem utilizadas no sistema de ensino, apontando de forma mais consistente como se dará o uso destas línguas em termos práticos, nos diferentes níveis de ensino. 
Os dois últimos documentos supracitados apresentam uma política de ensino de línguas que desde o início do ingresso escolar prevê o uso do português e do tétum. No plano curricular de 2005, a orientação é para que o professor inicie o trabalho principalmente com a oralidade em tétum e depois em português e progressivamente comece a introduzir a escrita em tétum e depois a escrita em língua portuguesa, fazendo com que ao longo do ensino primário o português se torne a principal língua de ensino. A Lei de Bases reafirma que as línguas de ensino são o tétum e o português e que um dos objetivos do ensino básico e propiciar o domínio das duas línguas e ainda a iniciação em uma língua estrangeira, afirmando ainda que o planeamento curricular das outras disciplinas, que passam a ser dadas no terceiro ciclo do ensino básico e no ensino secundário deve privilegiar o uso da língua portuguesa.

Estes documentos complementares à política constitucional definida é que tem dado materialidade à política linguística do país. Nesta materialização diversos atores têm interagido e os debates continuam intensos, pois não se trata somente de uma questão técnica, mas de uma questão ideológica, na qual estão envolvidas diferentes concepções teóricas de política linguística e de política de ensino de línguas e os interesses econômicos e geopolíticos de quem atua nos espaços onde se debatem estas políticas.

Um ponto sensível neste debate é a questão das demais línguas nacionais que não estão nomeadas na constituição e que são as línguas maternas da maioria dos timorenses. Atualmente os documentos não reservam nenhum espaço ao ensino destas línguas no espaço escolar e o apoio às iniciativas do INL para a preservação das línguas nacionais, devido a falta de interesse político e de recursos financeiros e materiais, tem sido muito pontual.

Esta questão tem sido um problema, pois o debate travado pela Organização das Nações Unidas para a Educação, a Ciência e a Cultura (UNESCO) e o Fundo das Nações Unidas para a Infância (UNICEF) na região, incluindo Timor-Leste, promovendo e incentivando o uso das línguas maternas na alfabetização e no letramento inicial, assim como a defesa de diversas ONGs dessa política tem gerado polêmica no país, uma vez que muitos líderes timorenses veem esta estratégia como uma forma de privilegiar o inglês e de retardar o ensino da língua portuguesa. Isso ocorreu, por exemplo, em 2008, no evento Ajudar as crianças a aprender: uma Conferência Internacional sobre Educação Bilingue em Timor-Leste (2008) quando houve debates acirrados a respeito da relação entre as línguas maternas e as línguas oficiais e o seu lugar no sistema de ensino. Tendo em vista que o projeto de reintrodução da língua portuguesa ainda está em andamen- 
to, o debate sobre as línguas maternas vem na contracorrente do processo de reinserção do português.

4. A política educacional e o ensino de língua portuguesa

Ao se falar de política educacional, política de ensino de línguas e o ensino de língua portuguesa em Timor-Leste é importante destacar que nenhum ano tem sido igual ao outro, a educação ocupa um papel central na reconstrução política de um país e as negociações para definir o andamento destas políticas nem sempre é fácil. Atualmente o Ministério da Educação lida com seis parceiros principais que contribuem na área de educação, Portugal, Brasil e Cuba, através de acordos de cooperação; Nova Zelândia, através da New Zealand Aid; o Banco Mundial e a Australian Aid, que atuam em conjunto, através de políticas de ajuda internacional e o UNICEF, através de acordo específico de colaboração. Afora isso, o Ministério da Educação conta com assessores internacionais de diversos países atuando nas mais diversas áreas e tem que lidar com 22 ONGs internacionais e nacionais que executam projetos na área educacional ${ }^{3}$.

Portugal tem desempenhado um papel fundamental no desenho das políticas educacionais de Timor-Leste, antes mesmo da independência. Na memória de muitos portugueses o ano de 1999 está intrinsecamente ligado ao acompanhamento diário do desenrolar da situação timorense, pois ao longo dos 24 anos de ocupação, apesar do pouco destaque político de Portugal no cenário internacional, os portugueses foram defensores intransigentes da causa timorense.

Neste sentido é que entre 2001 e 2002 foi possível alocar 145 professores portugueses para trabalhar com o ensino de língua portuguesa nos 13 distritos de Timor-Leste, atuando principalmente com formação de professores, mas também dando cursos independentes; data deste período também o início do curso de Licenciatura em Língua Portuguesa e Culturas Lusófonas, realizado em parceria entre o Instituto Camões e a Universidade Nacional Timor Lorosa'e e as primeiras conversações desta universidade para o estabelecimento de cursos de nível superior em língua portuguesa, em parceria com a F.U.P. (Fundação das Universida-

Foi possível ter este panorama no encontro denominado Avaliação Anual Conjunta (2008), que ocorre anualmente reunindo os diversos parceiros que atuam na área educacional. 
des Portuguesas), bem como o envio de estudantes timorenses para cursar o nível técnico, superior e a pós-graduação em Portugal (Bolina, 2005).

Ao longo dos anos este projeto foi evoluindo ampliando o seu campo de atuação. Hoje em dia o que é denominado "Projeto de Reintrodução da Língua Portuguesa” tem como objetivos globais: o apoio à reconstrução do sistema educativo de Timor-Leste e o desenvolvimento do domínio da língua portuguesa. Como objetivos específicos o projeto aponta para o reforço da capacitaçao dos docentes em língua portuguesa e também ao nível científico, didático e pedagógico; a capacitação de funcionários públicos e a difusão, de um modo geral, do português, principalmente via apoio a TVTL (Televisão de Timor-Leste) e a radiodifusão. Atualmente o projeto conta com 120 docentes portugueses, 170 formadores timorenses e 103 funcionários de apoio ${ }^{4}$.

Afora os projetos supracitados que continuam em andamento, um dos maiores projetos executados no âmbito da formação de professores é o programa, denominado de Bacharelato, que é uma parceria entre as cooperações portuguesa e brasileira. O programa é uma formação de três anos, em nível superior, em língua portuguesa e ao nível pedagógico e científico para a docência nas séries iniciais e das disciplinas de língua portuguesa, biologia, matemática, física, química, história e geografia, no terceiro ciclo do ensino básico e no ensino secundário 5 .

Nos anos de 2001/2002 foi estabelecido também o plano gradual de substituição da língua indonésia pela língua portuguesa no sistema escolar, neste plano, os dois primeiros anos do primário começaram a ter aulas em português e tétum, sendo que progressivamente a partir de então, os alunos passariam a ter aulas em português na escola, até que todo sistema de ensino básico fosse em tétum e língua portuguesa e o secundário somente em língua portuguesa (Bolina, 2005, p. 186).

Atualmente todo o antigo ensino primário de seis anos tem aulas em língua portuguesa e em tétum. O antigo ensino pré-secundário de três anos, que agora é o terceiro ciclo do ensino básico, começou mais recentemente a ter aulas em língua portuguesa. O desafio neste nível de ensino é maior,

4 Estas informações foram apresentadas no Plano de Actividades 2009 (2008) da Cooperação Portuguesa, na Avaliação Anual Conjunta (2008).

5 O programa de bacharelato foi apresentado na Avaliação Anual Conjunta (2008) no referido Plano de Atividades 2009 (2008) pela Cooperação Portuguesa e no resumo do Programa de Qualificação de Docente e Ensino de Lingua Portuguesa de Timor-Leste (2008) pela Cooperação Brasileira. 
pois como o ensino passa a ser multidisciplinar com vários professores que foram escolarizados e que se formaram através do sistema indonésio, dando aulas até recentemente em indonésio, a resistência a língua portuguesa é mais presente. $\mathrm{O}$ mesmo ocorrendo com o ensino secundário que em breve obrigatoriamente deverá adotar o português em todas as disciplinas, fazendo com que o maior desafio da política de ensino de línguas de TimorLeste neste momento seja a introdução da língua portuguesa nestes dois níveis de ensino. O próximo nível, que será o superior, onde a língua portuguesa deverá ser reinserida nos próximos anos em todos os cursos representará também um desafio político para a política linguística timorense.

A cooperação brasileira desempenha um papel importante também no contexto de reintrodução da língua portuguesa em Timor-Leste. Embora o Acordo de Cooperação na área de educação remeta a 2002, com medidas que foram tomadas pela Agência Brasileira de Cooperação, com a fundação de um Centro de Formação Profissional e um projeto de alfabetização comunitária, é somente no ano de 2003 com a ida da primeira missão de especialistas brasileiros que começa de fato uma cooperação mais estreita que responde não só as demandas mais imediatas, mas que intervêm também na formulação das políticas. Em 2005, o projeto entra numa nova fase com o envio de 50 especialistas na área de educação que será o embrião do atual Programa de Qualificação de Docente e Ensino de Língua Portuguesa em Timor-Leste que passará a ser gerido pela CAPES ${ }^{6}$.

Atualmente sob a gestão desta instituição existem quatro programas ativos em Timor-Leste: o PROFEP (Programa de Formação de Professores do Ensino Primário), o PROCAPES (Programa de Formaçao de Professores do Ensino Pré-Secundário e Secundário), o ELPI (Ensino de Língua Portuguesa Instrumental) e o Programa de Especialização em Educação da Universidade Nacional Timor Lorosa'e (UNTL) (Programa...2008).

Neste momento, que ainda é de transição, as duas cooperações brasileira e portuguesa são as principais responsáveis pela reintrodução da língua portuguesa no sistema educacional timorense, embora seja importante destacar o trabalho cubano com a alfabetização de adultos em português e em tétum e a mobilização feita pelo UNICEF, em torno da construção do currículo do ensino primário e dos guias didáticos para as séries iniciais, que começaram a ser distribuídos para os professores ${ }^{7}$. O UNICEF contratou também recentemente, através de chamada pública, a Universidade do

6 Apresentação do Programa de Qualificação de Docente e Ensino de Lingua Portuguesa de TimorLeste (2008), na Avaliação Anual Conjunta (2008) 
Minho para trabalhar na reelaboração do currículo do terceiro ciclo do ensino básico, o antigo ensino pré-secundário (Termos de Referência, 2008 e Universidade do Minho, 2009).

Mesmo com estes apoios, Timor-Leste tem enfrentado uma série de desafios políticos para a implementação da reintrodução da língua portuguesa, a começar pela dificuldade do quadro técnico do Ministério da Educação, primeiro em lidar com uma diversidade de cooperações e que não dialogam de forma apropriada entre si e segundo de planejar um projeto de educação no país de acordo com as necessidades de um país em desenvolvimento e de acordo com o que foi discutido pela população nos dois Congressos Nacionais de Educação que foram realizados em 2003 e $2008^{8}$.

Em sala de aula os desafios não são mais fáceis, no ensino primário, os professores ainda ensinam utilizando a metodologia tradicional do leia e copie, que nem sempre implica leitura, e embora muitos dos professores falem o português e o tétum, nem sempre o domínio destas línguas é suficiente para que possam ensiná-la. ${ }^{9}$ Contudo, os materiais produzidos especialmente para Timor-Leste pela Editora Lidel, de Portugal, baseados no Quadro Europeu Comum de Referência para as Línguas (2001) estão começando a chegar aos professores e como foram elaborados de acordo com concepções mais atuais de ensino de línguas podem, se for dada a devida formação aos docentes, ter um impacto positivo no ensino ${ }^{10}$.

Embora pareça que progressivamente a situação esteja melhorando nas séries iniciais, o processo no terceiro ciclo do ensino básico e no ensino secundário parece que será mais longo. No caso da língua portuguesa, afora a falta de formação dos professores nesta língua, os professores que trabalham com o português como disciplina não têm muitos materiais para estes níveis de ensino. O principal livro acessível chamado

$7 \mathrm{Na}$ Avaliação Anual Conjunta (2008) houveram apresentações do UNICEF e da Cooperação Cubana em que foram detalhadas estas atividades.

8 Os Congressos Nacionais de Educação de Timor-Leste deliberaram as diretrizes para a educação do país, mas o Ministério da Educação tem autonomia para acatar ou não as diretrizes apontadas.

9 Estas observações e as demais que se seguem sobre a situação do ensino de língua portuguesa foram feitas durante os anos de 2008 e 2009 através do acompanhamento das atividades de pesquisa e docência das alunas da 2 a edição do Programa de Especialização em Educação, da Faculdade de Ciências da Educação, da UNTL, do curso de língua portuguesa, realizado no âmbito do Programa de Qualificaşão de Docente e Ensino de Lingua Portuguesa da CAPES, em parceria com a UNTL, no qual atuei como professor.

10 Isso pode ser visto no Catálogo 2009 (2008) da Lidel. 
Português em Timor (Coimbra e Coimbra, 2003) é uma adaptação de um método antigo de ensino de português para estrangeiros, apresentando diversos problemas em termos de concepções teóricas de ensino de línguas que se reflete na forma e nos conteúdos do material.

A ausência de um currículo para o terceiro ciclo do ensino básico e para o ensino secundário tem sido um problema também tanto para definição do conteúdo da fossação de professores nos cursos de bacharelato, dados pelos professores portugueses e brasileiros, assim como para o desenvolvimento de materiais didáticos e de programas especiais de formação para os professores destes níveis.

A superlotação das salas de aula que chegam a ter 50 alunos nestes níveis de ensino, o desinteresse dos mesmos que foram alfabetizados em indonésio e depois tiveram que transitar para o português geram problemas na aprendizagem desta língua. $\mathrm{O}$ uso de metodologias inadequadas torna por vezes o ensino desinteressante, uma vez que o privilégio dado ao conhecimento gramatical e o pouco trabalho com as habilidades de fala e escuta e de leitura e escrita tem gerado um domínio superficial da língua portuguesa.

Apesar disso no Censo de 2004 36,8\% dos timorenses declararam saber falar, ler e escrever em português e $85,6 \%$ declararam saber falar, ler e escrever o tétum (Censos de Prioridade Nacional, 2004). O número que parece elevado não registra os diferentes níveis de domínio da língua, que poder ir de uma capacidade de comunicação essencial a um domínio avançado de leitura e escrita. Mas o dado revela de qualquer maneira, uma expansão da língua portuguesa e também do tétum oficial desde o período da independência, quando os indicadores revelavam que este número não passava de 5\% (Bolina, 2005, p. 185), e é um indício do poder simbólico destas línguas no país neste momento. Ainda que pesem as dificuldades encontradas no ensino da língua portuguesa, relacionadas ao planejamento das políticas linguística e de ensino de línguas, o trabalho constante em torno do desenvolvimento das mesmas aponta para um futuro animador. A aprovação da Lei de Bases, em 2008, o desenvolvimento e a distribuição dos guias do professor para o trabalho com o currículo, o início da construção do plano curricular do terceiro ciclo do ensino básico, ao qual certamente deve se seguir o desenvolvimento do que é referente ao ensino secundário, revelam que qualquer avaliação precipitada com relação às políticas que estão sendo implementadas seria prematuro. 
5. Desafios políticos de um contexto multilingue: um debate em TimorLeste

Em um documentário norte-americano recente chamado The Linguists (2008), dois linguistas da área de línguas indígenas se auto-retratam como uma espécie de caçadores de aventuras em busca de línguas em extinção. Eles vão a lugares remotos do mundo como a Sibéria, o interior da India e da Bolívia, na tentativa de registrar línguas que estão prestes a desaparecer. Nas viagens que aparecem no filme, eles passam alguns dias nestas aldeias e recolhem alguns dados linguísticos. $\mathrm{Na}$ aldeia indiana escolhida para pesquisa, a princípio, eles lamentam o fato de que as crianças estudem na escola em inglês e em uma das línguas regionais indianas e não na sua língua materna. Contudo, numa outra cena do documentário gravada posteriormente, comentando a posição que eles tomaram no momento da visita, eles reavaliam as suas posturas e reconhecem a necessidade daquelas crianças terem de aprender estas outras línguas para garantir a sua inserção social futura.

Esta história é para rememorar a necessidade dos linguistas e dos responsáveis pelas políticas linguísticas e de ensino de línguas avaliarem com cuidado cada situação sociolinguística e compreender a diversidade dos contextos que implicam em diferentes políticas, antes da crítica a um determinado modelo ou a proposição de um novo.

A título de exemplo um discurso que tem sido utilizado de forma unilateral no Sudeste Asiático por agências internacionais de desenvolvimento como a UNESCO e o UNICEF e por grandes ONGs que trabalham com infância no âmbito internacional, como, por exemplo, a CARE se refere às vantagens cognitivas e psicossociais do ensino em língua materna nas séries iniciais, em países subdesenvolvidos com contextos sociolinguisticamente complexos ${ }^{11}$.

$\mathrm{Na}$ referida conferência Ajudar as Crianças a Aprender: Uma Conferência Internacional sobre Educação Bilingue em Timor-Leste, realizada em 2008, pelo Ministério da Educação timorense, com o patrocínio das instituições supracitadas, por exemplo, o problema começa com o próprio título da conferência que já indicia uma posição de que o ensino bilíngue/ multilíngue necessariamente vai contribuir para a melhoria da aprendizagem das crianças timorenses. $\mathrm{O}$ documento opera com este discurso ao

11 Isso pode ser observado, por exemplo, nos documentos disponíveis para download, na página da UNESCO, em www.unescobkk.org 
longo de todo relatório, minimizando os eventuais problemas que podem ser encontrados ao longo do processo de implementação de projetos de ensino com este viés. Não que seja o caso de negar as vantagens cognitivas no processo de aprendizagem das crianças que utilizam a língua materna, nos diversos trabalhos de Cummins (2000) e Hornberger (1998) e de outros tem sido verificado que efetivamente, mesmo em contextos muito diferenciados, as crianças que iniciam o seu processo de escolarização em língua materna têm melhores condições de aprendizagem e de dar prosseguimento aos estudos, afora as vantagens psicossociais em termos de valorização e reconhecimento do valor da própria língua e da sua própria identidade.

Mas as vantagens cognitivas e psicossociais da aprendizagem bilíngue/multilíngue não podem ser utilizadas como argumentos incontestáveis para o ensino em língua materna em detrimento de pesquisas cuidadosas aprofundadas sobre cada contexto, onde a política pode ser implementada. Isso é o que parece estar ocorrendo em Timor-Leste, atualmente, embora exista uma pressão destas agências internacionais para que haja um espaço maior das línguas maternas no ensino, faltam pesquisas sociolinguísticas para saber não só o conhecimento dos timorenses das diversas línguas do seu país, como também o nível de domínio destas línguas. No caso das crianças, é fato que em algumas regiões o tétum não está muito presente, mas ao mesmo também é possível constatar que muitos professores locais têm uma sensibilidade para trabalhar com os seus alunos, utilizando a língua local para mediar a aprendizagem do tétum e do português. Embora a necessidade da pesquisa tenha sido pautada no texto dos relatórios da conferência supracitada, no documento o ensino em língua materna parece ser a solução para os atuais problemas no ensino, ignorando-se o fato de que o processo de implementação da política linguística atual e da política de ensino de línguas ainda está em andamento.

É importante ainda destacar que o bilinguismo/multilinguismo com diversos níveis de proficiência da população timorense revela uma grande facilidade destes em aprender as diferentes línguas locais. Hull (2001 apud Engelenhoven, 2006) atribui isso ao fato de que Timor-Leste constitui um Spracbbund, o que significa que as diferentes línguas locais, independentemente de suas origens genéticas, possuem uma convergência gramatical. Isso quer dizer que para um timorense aprender outra língua local, ele precisa apenas adquirir um novo léxico e não necessariamente aprender um novo conjunto de conhecimentos gramaticais. Este é 
um importante fator a ser levado em conta na política de ensino de línguas, pois revela que o multilinguismo faz parte da realidade social do país, não sendo dependente da política de ensino adotada, representando uma necessidade cotidiana para os timorenses que já estão habituados ao uso de diversas línguas, ainda que os níveis de proficiência em cada uma delas seja diferenciado.

Afora esta questão, algo importante a ser considerado é a importância simbólica e neste momento estratégica também do ensino de língua portuguesa, no sentido de garantir a autonomia política de Timor-Leste, a qual se soma um fator de ordem linguística, a diglossia (Engelenhoven, 2006). Historicamente as línguas de Timor-Leste apresentaram um padrão diglóssico, com a convivência de dois registros, um coloquial e um ritual. A língua portuguesa se inseriu neste padrão ao longo dos séculos XVIII e XIX com a extensão deste padrão diglóssico (Engelenhoven, 2006), fazendo com que as línguas nativas passassem a ocupar os espaços informais e o português o espaço formal. Este uso da língua portuguesa é mais um fator a ser levado em consideração no olhar para as políticas linguísticas e de ensino em Timor-Leste, pois revela que a língua portuguesa não é um elemento estranho no panorama linguístico timorense, aparecendo não só nos empréstimos lexicais de diversas línguas, mas também ocupando um papel estrutural nas relações entre as diversas línguas locais.

Neste sentido, a política linguística e de ensino de línguas de TimorLeste é pertinente do ponto de vista não só político e histórico e linguístico, mas se insere no próprio padrão de organização dos povos timorenses, não representando também nenhum risco maior ou menor de fracasso escolar para as crianças timorenses.

Por fim, a falta de uma política linguística para a inserção das línguas maternas no sistema de ensino neste momento parece ser mais uma situação temporária, do que uma exclusão definitiva destas línguas deste sistema. Como a implementação do tétum e do português neste momento é uma questão prioritária, ao que tudo indica até este processo chegar a um bom termo, inevitavelmente as línguas locais ficaram oficialmente fora da escola, mas certamente operando como pontes de aprendizagem em função das demandas de cada comunidade. A existência inevitável destas pontes e o grande interesse dos timorenses que agora estão se formando em língua portuguesa, em pesquisar e documentar as suas línguas locais apontam para um futuro, em que cada vez mais estas línguas passarão a fazer parte da escola. 


\section{Bibliografia}

AJUDAR AS CRIANÇAS A APRENDER: UMA CONFERÊNCIA INTERNACIONAL SOBRE EDUCAÇÃO BILINGUE EM TIMOR-LESTE (2008) Díli, Timor-Leste: Ministério da Educação, vol. I e II.

ATLAS DE TIMOR-LESTE (2002) Lisboa: Lidel.

AVALIAÇÃO ANUAL CONJUNTA (2008) Díli, Timor-Leste: Ministério da Educação. BOLINA, M. (2005) Timor e a Língua Portuguesa no seu Projeto Educativo. Revista Lusófona de Educação, 6, p. 179-193.

BULATAO, R. et al. (2008) Nota de Políticas sobre Crescimento Populacional e Implicações para TimorLeste. Díli, Timor-Leste: Banco Mundial. Disponível em: < http://siteresources.worldbank. org/INTIMORLESTE/

Resources/PopulationGrowth2008portu.pdf > Acesso em: 10 de agosto de 2009.

CATÁLOGO 2009 LÍNGUA PORTUGUESA TIMOR-LESTE (2008). Lisboa: Lidel. Disponível em: < www.lidel.pt > Acesso em: 10 de agosto de 2009.

CENSOS DE PRIORIDADE NACIONAL (2004) Disponível em: < http:// dne.mof.gov.tl/census/tables/national/

index.htm > Acesso em: 10 de agosto de 2009.

COIMBRA, I e COIMBRA, O. M. (2003) Português em Timor. Lisboa: Lidel.

CUMMINS, J. (2000) Language, power, and pedagogy. Bilingual cbildren in the crossfire. Clevedon, England: Multilingual Matters.

ENGELENHOVEN, A. (2006) Ita-nia Nasaun Oin-Ida, Ita-nia Dalen Sira Oin-seluk “Our Nation is One, our Languages are Different" Language Policy in East Timor In SEIXAS, P. C. e ENGELENHOVEN, A. (2006) Diversidade Cultural na Construção da Nação e do Estado em Timor-Leste. Porto: Edições Universidade Fernando Pessoa.

HORNBERGER, N. H. (1998) Language policy, language education, language rights: Indigenous, immigrant, and international perspectives. Language in Society, 27, 439-458.

HULL, G. (1998) The Basic Lexical Affinities of Timor's Austronesian Languages: A Preliminary Investigation. SLCET 1, p. 97-202 apud ENGELENHOVEN, A. (2006) Itania Nasaun Oin-Ida, Ita-nia Dalen Sira Oin-seluk "Our Nation is One, our Languages are Different” Language Policy in East Timor In SEIXAS, P. C. e ENGELENHOVEN, A. (2006) Diversidade Cultural na Construção da Nação e do Estado em Timor-Leste. Porto: Edições Universidade Fernando Pessoa.

HULL, G. (2001) A morphological overview of the Timoric Sprachbund, SLCET 4: 98205. apud ENGELENHOVEN, A. (2006) Ita-nia Nasaun Oin-Ida, Ita-nia Dalen Sira Oin-seluk "Our Nation is One, our Languages are Different" Language Policy in East Timor In SEIXAS, P. C. e ENGELENHOVEN, A. (2006) Diversidade Cultural na Construção da Nação e do Estado em Timor-Leste. Porto: Edições Universidade Fernando Pessoa.

HULL, G. (2001) Timor-Leste, Identidade, Lingua e Política Educional. Lisboa: Instituto Camões. HUMAN DEVELOPMENT REPORT 2007/2008 (2007) New York: United Nations Development Program. Disponível em: http://hdr.undp.org/en/media/HDR 20072008_EN_Complete.pdf > Acesso em: 10 agosto 2009.

MARQUES, A. H. O. (1998-2003) História dos Portugueses no Extremo Oriente, Lisboa: Fundação Oriente. 
PLANO CURRICULAR PARA O ENSINO PRIMÁRIO (2005) Díli, Timor-Leste: Direção Nacional de Currículos, Ministério da Educação e da Cultura.

PLANO DE ACTIVIDADES (2009) Díli, Timor-Leste: Cooperação Portuguesa Educação In AVALIAÇÃO ANUAL CONJUNTA (2008) Díli, Timor-Leste: Ministério da Educação.

PROGRAMA DE QUALIFICAÇÃO DE DOCENTE E ENSINO DE LÍNGUA PORTUGUESA (2008) Díli: Timor-Leste: Embaixada do Brasil em Timor-Leste In AVALIAÇÃO ANUAL CONJUNTA (2008). Díli, Timor-Leste: Ministério da Educação.

QUADRO EUROPEU COMUM DE REFERÊNCIA PARA AS LÍNGUAS APRENDIZAGEM, ENSINO, AVALIAÇÃO (2001) Porto: Edições Asa.

REVISTA CAMÕES. (2001) Timor Lorosa'e. v. 14, jul-set. Lisboa: Instituito Camões.

TERMOS DE REFERÊNCIA (TDR) PARA CONTRATO INSTITUCIONAL (2008)

Díli: UNICEF- Timor-Leste. Disponível em: < w3.dren.min-edu.pt/.../20081119104009

1.Pre_Secondary_Curriculum_TOR_Port.doc > Acesso em 10 agosto 2009.

THE LINGUISTS (2008). Direção: Seth Kramer, Daniel A. Miller. USA, 65 min.

THOMAZ, L. F. R. (2002). Babel Loro Sa'e - O Problema Linguistico de Timor-Leste. Lisboa: Instituto Camões.

TIMOR-LESTE (2002). Constituição. Constituição da República Democrática de Timor-Leste: promulgada em 20 de maio de 2002. Disponível em: <www.gov.east-timor.org/ PMpage1.htm > Acesso em: 10 agosto 2009.

TIMOR-LESTE. (2004). Decreto n. 1 de 14 de abril de 2004. Dispõe sobre o Padrão Ortográfico do Tétum. Lex: Jornal da República, Díli, Timor-Leste, Série I, n. 5, p. 417. TIMOR-LESTE. (2008). Lei n. 14 de 29 de outubro de 2008. Dispõe sobre as Bases da Educação. Lex: Jornal da República, Díli, Timor-Leste, Série I, n. 40, p. 2641-2648.

TIMOR-LESTE EM NÚMEROS (2008) Díli, Timor-Leste: Direção Nacional de Estatística, Ministério das Finanças. Disponível em: < www.dne.mof.gov.tl > Acesso em: 10 agosto 2009.

UNIVERSIDADE DO MINHO DESENVOLVE CURRÍCULOS PARA O ENSINO BÁSICO (2009) Disponível em: < http://timorlorosaenacao.blogspot.com/2009/ 06/universidade-do-minho-desenvolve.html > Acesso em: 10 agosto 2009. 